\title{
Optimal Ordering and Disposing Policies in the Presence of an Overconfident Retailer: A Stackelberg Game
}

\author{
Zhigang Wang, ${ }^{1}$ Zhenchao Zhang, ${ }^{2}$ Chunfa Li, ${ }^{2}$ Lei Xu, ${ }^{2}$ and Chang You ${ }^{3}$ \\ ${ }^{1}$ School of Electrical Engineering, Tianjin University of Technology, Tianjin 300391, China \\ ${ }^{2}$ School of Management, Tianjin University of Technology, Tianjin 300391, China \\ ${ }^{3}$ Naveen Jindal School of Management, University of Texas at Dallas, Richardson, TX 75080, USA \\ Correspondence should be addressed to Lei Xu; chully.xu@gmail.com
}

Received 6 August 2014; Revised 29 October 2014; Accepted 13 November 2014

Academic Editor: Tsan-Ming Choi

Copyright (C) 2015 Zhigang Wang et al. This is an open access article distributed under the Creative Commons Attribution License, which permits unrestricted use, distribution, and reproduction in any medium, provided the original work is properly cited.

\begin{abstract}
This paper investigates the impact of the retailer's overconfident behavior on supply chain performance. We start with a basic model on the rational newsvendor model and investigate the retailer's optimal ordering decision and expected profit. Next, we extend the basic model and introduce an overconfident retailer. We find that the retailer's overconfident behavior does not necessarily damage the supply chain compared with the basic model when the overconfident level does not exceed a threshold. We also design the cooperation and buyback mechanism and conduct numerical analysis to compare the manufacturer's and retailer's expected profits and real profits with those in the basic newsvendor model. It can achieve Pareto improvement in the supply chain when the overconfident level is low. When the retailer's overconfident level exceeds a threshold, the retailer's ordering decision cannot make the whole supply chain sustainable development.
\end{abstract}

\section{Introduction}

As a classical model in MS/OM, the newsvendor problem has been deeply explored; however, in reality the actual ordering of the newsvendor always deviates from the theoretically optimal result, and the actual ordering fluctuates around the theoretically optimal ordering quantity. Most scholars use the classical economic assumption that the decision-maker is a rational man, while he/she often has different decisionmaking behavior, and it is also illustrated in psychology that people cannot be entirely rational and often make irrational decisions $[1,2]$.

In recent years, decision-making has been becoming a hot issue along with the fact that consumer behavior was introduced into operational management. Scholars have proved the bias between cognitive reflection and decisionmaking by experiment and the decision-makers are prone to risk preferences, fairness preferences, eye tracking social preferences, overconfidence, and other preferences (see [3-7]). Among them, overconfident behavior becomes one of the hot spots and affects the operation management of the enterprise seriously. For instance, the high volume-trading problem [8], the bankruptcy because of the crazy mergers made by CEO [9], and the presence of oil or gas predicted by young geologist too confidently led to loss of millions of dollars [10]. Overconfidence has been explored deeply in the field of behavioral psychology, behavioral finance, and behavioral management but rarely in the field of management science and operations management. Croson et al. [11] first introduce overconfident behavior in supply chain management.

Based on the classical newsvendor model, we focus on the order variance when the decision-makers are overconfident and rational, respectively. Considering the cooperation and buyback mode, this paper illustrates how the retailer's overconfident behavior affects her ordering decision and the profit of each member in the whole supply chain and how the manufacturer responds to encourage the overconfident retailer to decide the systematic optimal ordering quantity. The remainder of this paper is organized as follows. Section 2 reviews the relevant literature, and Section 3 describes the basic problem. Sections 4 and 5 discuss the basic model and overconfident retailer model, respectively. Section 6 discusses 
two kinds of decision-making mechanisms, the cooperation mode and buyback mode, and reports the results of an extensive numerical study, and Section 7 concludes this paper with a discussion of the results.

\section{Literature Review}

There are two primary streams of research that relate to our analysis: the literature on newsvendor problem and overconfident behavior. The newsvendor problem is a classic supply chain management issue which has been proposed in the fifties of the last century and has received wide attention in academia. Arrow et al. [12] analyzed the famous critical fractile solution for the newsvendor problem; after that, many scholars regard maximizing the expected profit as a decision objective and use the expected utility theory and mathematical model to explore the newsvendor problem. For example, Whitin [13] develops the newsvendor model where the demand is price dependent and follows a uniform distribution; moreover, he finds the optimal order which depends on the price variance under the objective of maximizing the expected profit. Thakkar et al. [14] investigated the optimal ordering quantity under the objective of maximizing the expected investment return and found wider application compared with the expected maximum. Khouja [15] classified the newsvendor problem into 11 categories, made a literature review on the predecessors' research, and provided recommendations for future research. For recent reviews on the newsvendor model, refer to Petruzzi and Dada [16] and Qin et al. [17]. None of these papers consider the decision-makers' decision behavior.

More recently, a stream of research has emerged that explored decision-makers' behavior. For example, Eeckhoudt et al. [18] studied the risk-aversion behavioral decisionmakers and found that decision-makers' ordering quantity is always lower than the optimal ordering quantity. Many scholars have used experimental evidence to verify the existence of decision deviation. Schweitzer and Cachon [4] explain why retailers' order differs from the expected profit-maximizing quantity and define the high (low) profit environment and find that decision-makers' ordering quantity is less than (greater than) the optimal ordering quantity under the high (low) profit environment by experiments. Benzion et al. [19] test participants' ordering decisions and show that the decision-makers have behavior preferences. In these behavioral preferences, the overconfident behavior is particularly prevalent and potentially harmful behavior [20]. Although many of these papers consider behavior preferences, few papers address the overconfident behavior in supply chain management.

Overconfident behavior is quite mature in psychology and has progress in the field of behavioral finance and behavioral management $[21,22]$. But in the field of supply chain inventory management, the research on overconfidence is rare. Moore and Healy [23] define three types of overconfidence: overestimation, overplacement, and overprecision. People overestimate their actual capabilities, overplace their position among their colleagues or peers, and believe they are better than others. They believe that their predictions are more accurate than they actually are. This paper is also based on the third definition. Croson et al. [11] summarize the previous experimental study on human behavior, citing the third definition [23] overprecision, and use salvage costs and price adjustments to revise the overconfident retailer's order decisions. Ren and Croson [24] and Proeger and Meub [25] provide experiment evidence for overconfidence as social bias. Unlike the present analysis, these papers do not analyze that the retailer's and manufacturer's profits can or cannot increase jointly after the implementation of the contract.

In this paper, we analyze the overconfident behavior in the traditional supply chain. In this setting, we consider a twoechelon supply chain that consists of one single manufacturer and one single retailer who is overconfident on the market demand. We discuss a basic model and then introduce an overconfident retailer. In addition, we also design the cooperation and buyback mechanisms and conduct a numerical analysis to compare the manufacturer's and retailer's expected profits and real profits with those in the basic newsvendor model.

\section{Problem Descriptions}

Consider a two-echelon supply chain, which is composed of one single manufacturer and one single retailer who has overconfident behavior on the market demand, and the manufacturer is the leader and the retailer is the follower in the supply chain. To be specific, the manufacturer is a risk-neutral decision-maker and does not have overconfident behavior, and the retailer is also a risk-neutral decision-maker and has overconfident behavior. The chronology of the event is that the manufacturer produces products and sells them to the retailer in wholesale price $w$, and the retailer sells these products to the market in selling price $p$. The manufacturer can predict the market demand $X$ accurately, and the demand $X$ follows a distribution with mean $\mu$ and variance $\sigma^{2}$ [11]. The market demand can be expressed as $X=\sigma \varepsilon+\mu$, where $\varepsilon$ is a random variable, whose mean is 0 and variance is 1 , and denote the CDF and PDF by $F(x)$ and $f(x)$.

For the overconfident retailer, there is a deviation between the forecast demand and the actual demand. Thus, the cumulative distribution function is $F_{a}\left(x_{a}\right)$ and the probability density function is $f_{a}\left(x_{a}\right)$. Refer to the definition of overconfidence defined by Moore and Healy [23], the forecast demand mean $\mu_{a}$ is not equal to the actual demand mean $\mu$ for the retailer overestimates the market environment and her ability. On the other hand, the overconfident retailer's demand variance $\sigma_{a}^{2}$ is less than or equal to the actual demand variance $\sigma^{2}$. Without loss of generality, the overconfident retailer's forecast demand can be expressed as

$$
X_{a}=\sigma_{a} \varepsilon+\mu_{a}=(1-a) \sigma \varepsilon+(1+a) \mu
$$

where $a$ indicates the retailer's overconfident level, and $0 \leq$ $a \leq 1$. When $a=0$, the retailer has no overconfident behavior; when $a=1$, we have $X_{a}=2 \mu$ and the retailer behaves in an extremely overconfident manner and believes 
that the demand is constant. The closer $a$ is to 1 , the more intense overconfidence the retailer behaves.

In the following discussion, let $c$ represent unit production cost. For unsold products, $s_{R}$ and $s_{M}$ represent unit salvage value that is disposed of by the retailer and manufacturer, respectively.

It is assumed that the above distribution functions are first-order differentiable and have strict monotone inverse function; these parameters satisfy the following relationship:

$$
c<w<p, \quad s_{R}<s_{M}<c,
$$

where the first constraint is to ensure the wholesale price is higher than the manufacturer's production cost and the retail price is higher than the wholesale price, in order to guarantee the retailer's and manufacturer's profits. The second constraint indicates that the residual value of the product is lower than the manufacturer's production cost, and the residual value of the product in the retailer is less than that in the manufacturer, which illustrates that the manufacturer has the advantage in disposing the unsold products.

\section{Basic Model}

In this section, we first discuss a basic model where the manufacturer and the retailer are risk-neutral and rational. We assume the market demand of the product is $X$, the demand distribution function $F(x)$ is continuous and differentiable and is strictly increasing, the average demand is $E(x)=\mu$, and the variance is $\operatorname{Var}(x)=\sigma^{2}$. The retailer's ordering quantity is $Q$. When the market demand satisfies $X<Q$, the sale quantity is $S(Q)=X$; otherwise, the sale quantity is $S(Q)=Q$. Thus, the expected sale quantity is $S(Q)=\min \{Q, X\}=$ $Q-\int_{0}^{Q} F(x) d x$, and the expected unsold quantity is $I(Q)=$ $Q-S(Q)=\int_{0}^{Q} F(x) d x$.

The retailer's and the manufacturer's profits are given by

$$
\begin{gathered}
\pi_{R}^{N}=p S(Q)+s_{R} I(Q)-w Q \\
=(p-w) Q-\left(p-s_{R}\right) \int_{0}^{Q} F(x) d x, \\
\pi_{M}^{N}=w Q-c Q .
\end{gathered}
$$

The profit of the supply chain is given by

$$
\begin{aligned}
\pi^{N} & =\pi_{R}^{N}+\pi_{M}^{N} \\
& =(p-c) Q-\left(p-s_{R}\right) \int_{0}^{Q} F(x) d x .
\end{aligned}
$$

The objective of the retailer is to choose $Q^{*}$ to maximize her profit. Besides, the expected profit function $\pi_{R}^{N}$ has a maximum because the second-order condition $\partial^{2} \pi / \partial Q^{2}<0$. Solving the first-order derivative of (3) with respect to $Q$, we can obtain

$$
F\left(Q^{N^{*}}\right)=\frac{p-w}{p-s_{R}} .
$$

Thus, $Q^{N^{*}}=F^{-1}\left((p-w) /\left(p-s_{R}\right)\right) . Q^{N^{*}}$ is the retailer's optimal ordering quantity in the newsvendor model, which is consistent with the results of Pasternack [26].

\section{Overconfident Retailer Model}

In this section, we consider an overconfident retailer who has an overconfident behavior on the market demand. In this case, the retailer's ordering quantity is $Q_{a}$. When the market demand satisfies $X_{a}<Q_{a}$, the sale quantity is $S_{a}\left(Q_{a}\right)=X_{a}$; otherwise, $S_{a}\left(Q_{a}\right)=Q_{a}$. Therefore, $S_{a}(Q)=\min \left\{Q_{a}, X_{a}\right\}$. It can be rewritten as

$$
\begin{aligned}
S_{a}\left(Q_{a}\right) & =\int_{0}^{Q_{a}} x_{a} f_{a}\left(x_{a}\right) d x_{a}+Q_{a} \int_{Q_{a}}^{\infty} f_{a}\left(x_{a}\right) d x_{a} \\
& =Q_{a}-\int_{0}^{Q_{a}} F_{a}\left(x_{a}\right) d x_{a} .
\end{aligned}
$$

The expected unsold quantity is $I_{a}\left(Q_{a}\right)=Q_{a}-S_{a}\left(Q_{a}\right)=$ $\int_{0}^{Q_{a}} F_{a}\left(x_{a}\right) d x$.

In order to facilitate comparison with the expected profit under the basic model, we examine the relationship on the optimal ordering quantity between the rational retailer and the overconfident retailer in Theorem 1.

Theorem 1. The overconfident retailer's optimal ordering quantity is

$$
Q_{a}^{*}=(1-a) Q^{N^{*}}+2 a \mu
$$

Proof. As discussed above, the rational retailer's optimal ordering quantity is $Q^{N^{*}}=F^{-1}\left[(p-w) /\left(p-s_{R}\right)\right]$, and we define $(p-w) /\left(p-s_{R}\right)=\rho$; that is, $\rho=F\left(Q^{N^{*}}\right)$.

Note that because $X=\sigma \varepsilon+\mu, X_{a}=\sigma_{a} \varepsilon+\mu_{a}=(1-$ a) $\sigma \varepsilon+(1+a) \mu$, and $X$ and $X_{a}$ follow the relationship that $X_{a}=(1-a) X+2 a \mu$, we have $F_{a}\left(x_{a}\right)=P((1-a) X+2 a \mu \leq$ $\left.x_{a}\right)=F\left[\left(x_{a}-2 a \mu\right) /(1-a)\right]$.

As a result, the overconfident retailer's optimal ordering quantity is $Q_{a}^{*}=F_{a}^{-1}\left[(p-w) /\left(p-s_{R}\right)\right]=F_{a}^{-1}(\rho)$.

And it can be rewritten as $\rho=P\left(X_{a} \leq Q_{a}^{*}\right)=P((1-a) X+$ $\left.2 a \mu \leq Q_{a}^{*}\right)=F\left[\left(Q_{a}^{*}-2 a \mu\right) /(1-a)\right]$.

Finally, we have $F\left(Q^{N^{*}}\right)=F\left[\left(Q_{a}^{*}-2 a \mu\right) /(1-a)\right]$; that is, $Q_{a}^{*}=(1-a) Q^{N *}+2 a \mu$.

Theorem 1 presents the overconfident retailer's optimal ordering policy, and based on this result, we can derive some properties of the optimal ordering policy as follows.

Corollary 2. When $Q^{N^{*}}<2 \mu, Q_{a}^{*}>Q^{N^{*}}$; otherwise, $Q_{a}^{*} \leq$ $Q^{N^{*}}$.

Proof. According to the result of Theorem 1 that $Q_{a}^{*}=(1-$ a) $Q^{N^{*}}+2 a \mu$, we can obtain $Q_{a}^{*}-Q^{N^{*}}=a\left(2 \mu-Q^{N^{*}}\right)$, so it is easy to obtain the conclusion of Corollary 2 . 
Subsequently, we consider the manufacturer's and retailer's expected profits separately. When the overconfident level is $a$, the retailer's expected profit can be expressed as

$$
\begin{aligned}
\pi_{R}^{a^{*}} & =E\left\{-w Q_{a}+p S_{a}\left(Q_{a}\right)+s_{R} I_{a}\left(Q_{a}\right)\right\} \\
& =(p-w) Q_{a}^{*}-\left(p-s_{R}\right) \int_{0}^{Q_{a}^{*}} F_{a}\left(x_{a}\right) d x_{a}
\end{aligned}
$$

where $x_{a}=(1-a) x+2 a \mu$.

Making variable substitution to (9) according to (8), it is easy to see

$$
\begin{aligned}
& \int_{0}^{Q_{a}^{*}} F_{a}\left(x_{a}\right) d x_{a} \\
& \quad=\int_{-2 a \mu /(1-a)}^{Q^{N^{*}}} F_{a}[(1-a) x+2 a \mu] d[(1-a) x+2 a \mu] \\
& \quad=(1-a) \int_{0}^{Q^{N^{*}}} F(x) d x .
\end{aligned}
$$

Bringing (8) and (10) into (9), we can get

$$
\begin{aligned}
\pi_{R}^{a^{*}}= & (p-w)(1-a) Q^{N^{*}}-\left(p-s_{R}\right)(1-a) \\
& \times \int_{0}^{Q^{N^{*}}} F(x) d x+2 a \mu(p-w) .
\end{aligned}
$$

In the same logic, the manufacturer's expected profit is

$$
\begin{aligned}
\pi_{M}^{a^{*}} & =E\left\{w Q_{a}-c Q_{a}\right\} \\
& =(w-c)(1-a) Q^{N^{*}}+2 a \mu(w-c)
\end{aligned}
$$

Under the conditions where the retailer disposes of the unsold products, the total profit of the supply chain is $\pi^{a^{*}}=$ $\pi_{M}^{a^{*}}+\pi_{R}^{a^{*}}$.

After simplifying, we can easily obtain $\pi^{a^{*}}=(p-c)(1-$ a) $Q^{N^{*}}-\left(p-s_{R}\right)(1-a) \int_{0}^{Q^{N^{*}}} F(x) d x+2 a \mu(p-c)$.

Based on the optimal profits of the rational and overconfident retailers, we can derive the following results.

Corollary 3. When $Q^{N^{*}}>2 \mu$, the expected profit of the whole supply chain in the overconfident newsvendor model is less than that in the basic newsvendor model, and the expected profit of the whole supply chain decreases with a. When $Q^{N^{*}}<2 \mu$, with a increasing, the expected profit of the whole supply chain in the overconfident newsvendor model has two cases: it is either higher or higher first and then lower than that in the basic newsvendor model.
Proof. Compared with the basic newsvendor model, the real profit difference is

$$
\begin{aligned}
\Delta \pi= & \pi^{N^{*}}-\pi^{a^{*}}=(p-c)\left(Q^{N^{*}}-Q_{a}^{*}\right) \\
& -\left(p-s_{R}\right) \int_{Q_{a}^{*}}^{Q^{N^{*}}} F(x) d x \\
= & a(p-c)\left(Q^{N^{*}}-2 \mu\right)-\left(p-s_{R}\right) \\
& \times \int_{(1-a) Q^{N^{*}}+2 a \mu}^{Q^{N^{*}}} F(x) d x .
\end{aligned}
$$

Therefore, solving the first-order derivative of $\Delta \pi$ with respect to $a$, we can obtain

$$
\begin{aligned}
\frac{\partial \Delta \pi}{\partial a}= & (p-c)\left(Q^{N^{*}}-2 \mu\right)+\left(p-s_{R}\right)\left(2 \mu-Q^{N^{*}}\right) \\
& \times F\left((1-a) Q^{N^{*}}+2 a \mu\right) \\
= & \left(p-s_{R}\right)\left(Q^{N^{*}}-2 \mu\right)\left[\frac{p-c}{p-w} F\left(Q^{N^{*}}\right)-F\left(Q_{a}^{*}\right)\right] .
\end{aligned}
$$

It is clear that $p-s_{R}>0$ and $1<(p-c) /(p-w)$. When $Q^{N^{*}}>2 \mu$, we have $Q_{a}^{*}<Q^{N^{*}}$. Since $F(Q)$ is an increasing function, this implies that $\partial \Delta \pi / \partial a$ is absolutely bigger than 0 ; that is, $\Delta \pi$ is increasing in $a$. In particular, when $a=0$, we have $\Delta \pi=0$. Therefore, the profit difference is increasing in a.

When $Q^{N^{*}}<2 \mu$, we have $Q_{a}^{*}>Q^{N^{*}}$ and $\partial \Delta \pi / \partial a=(p-$ $\left.s_{R}\right)\left(Q^{N^{*}}-2 \mu\right)\left[((p-c) /(p-w)) F\left(Q^{N^{*}}\right)-F\left(Q^{N^{*}}+(2 \mu-\right.\right.$ $\left.\left.Q^{N^{*}}\right) a\right)$ ] and when $a$ is low, there is $r$ which made the equation $r F\left(Q^{N^{*}}\right)=F\left(Q^{N^{*}}+\left(2 \mu-Q^{N^{*}}\right) a\right)$ set-up and satisfied $1<r<$ $(p-c) /(p-w)$; that is, $\partial \Delta \pi / \partial a$ is always less than zero; when $a=1, F\left(Q^{N^{*}}+\left(2 \mu-Q^{N^{*}}\right) a\right)=F(2 \mu)$, and if $(p-c) /(p-$ $w) F\left(Q^{N^{*}}\right)>F(2 \mu), \partial \Delta \pi / \partial a$ is less than zero, and the profit difference decreases with $a$; if $(p-c) /(p-w) F\left(Q^{N^{*}}\right)<F(2 \mu)$, $\partial \Delta \pi / \partial a$ is first less and then greater than zero and the profit difference is first decreasing and then is increasing in $a$.

From Theorem 1 and Corollaries 2 and 3, we find that if $Q^{N^{*}}<2 \mu$, then $d Q_{a}^{*} / d a=2 \mu-Q^{N^{*}}>0$; thus, we have $\pi_{M}^{a}>\pi_{M}$ and $\pi_{R}^{a}<\pi_{R}$, whereas if $Q^{N^{*}}>2 \mu, d Q_{a}^{*} / d a=$ $2 \mu-Q^{N^{*}}<0$; thus, $\pi_{M}^{a}<\pi_{M}, \pi_{R}^{a}<\pi_{R}$. In other words, the bigger $a$ is, the bigger the ordering quantity deviates from the optimal one and results in lower profit.

Just as analyzed in Section 2, Gervais et al. [22], Glaser and Weber [8], and Malmendier and Tate [9] have provided enough evidences in financial field. We find that the overconfident behavior does not necessarily damage the supply chain, if the manufacturer can take advantage of the retailer's overconfident behavior properly, such as subsidy or profit sharing mechanism which can improve the supply chain performance effectively. However, in the decentralized decision, both the retailer and the manufacturer maximize their own 
profits, and their decisions cause a double marginalization effect. What is worse, the overconfident behavior inevitably makes the retailer's profit losses.

We know that $Q_{a}^{*}<Q^{N^{*}}$ when $Q^{N^{*}}>2 \mu$; besides, the bigger $w$ is, the bigger $Q_{a}^{*}$ deviates from $Q^{N^{*}}$ and the lower the retailer's profit is; when $Q^{N^{*}}<2 \mu$, then $Q_{a}^{*}>Q^{N^{*}}$, and increasing $w$ leads to $\pi_{R}^{a^{*}}<\pi_{R}^{N^{*}}$. Therefore, the manufacturer should sell products to the retailer with low wholesale price, which could reduce the retailer's cost and then promote the retailer's ordering quantity and profit.

\section{Disposing Mechanism on Salvage Products}

Based on the analysis of the impact of the retailer's overconfident behavior on the supply chain, as a leader in the supply chain, the manufacturer should take effective measures to promote the retailer's ordering decisions. Herz et al. [27], Choi et al. [28], and Govindan et al. [29] have done relevant research on supply chain coordination. Xu et al. [30] and Huang et al. [31] also analyzed such practical problems. In this section, we try to design and analyze two coordination mechanisms: cooperation mode and buyback mode.

6.1. Cooperation Mode. In this mode, we consider the manufacturer and retailer cooperate to dispose of the unsold products to realize a "win-win" situation. It is assumed that $s_{M}>s_{R}$, which means that the manufacturer has the advantage in the disposing of the unsold products; therefore, the manufacturer disposes of the unsold products at the end of selling season. We also assume that the allocation rate of the residual value is $\lambda$. For unsold product, the manufacturer's benefit is $\lambda\left(s_{M}-s_{R}\right)$ and the retailer's benefit is $s_{R}+(1-\lambda)\left(s_{M^{-}}\right.$ $\left.s_{R}\right)$.

We assume that the manufacturer knows the retailer's overconfident level, and to manufacturer, the cost of the disposing of the unsold products is zero. Similar to the basic newsvendor model, in the corporation mode, the retailer believes her expected profit is

$$
\begin{aligned}
\pi_{R}^{a c}= & E\left\{p S(Q)+\left[s_{R}+(1-\lambda)\left(s_{M}-s_{R}\right)\right] I(Q)-w Q\right\} \\
= & (p-w) Q^{a c}-\left[p-s_{R}-(1-\lambda)\left(s_{M}-s_{R}\right)\right] \\
& \times \int_{0}^{Q^{a c}} F_{a}\left(x_{a}\right) d x_{a} .
\end{aligned}
$$

Solving the first-order derivative of (15) with respect to $Q^{a c}$, we can derive the optimal ordering quantity as follows

$$
Q^{a c^{*}}=F_{a}^{-1}\left[\frac{p-w}{p-s_{R}-(1-\lambda)\left(s_{M}-s_{R}\right)}\right] .
$$

From (16), the ordering quantity is increasing in $1-$ $\lambda$. Therefore, a proper incentive can instruct the retailer to choose a proper ordering quantity.
The retailer believes that her profit is maximal when the optimal ordering quantity is (16). However, it is up to the actual market demand. Therefore, her real expected profit is

$$
\begin{aligned}
\pi_{R}^{a c^{*}}= & (p-w) Q^{a c^{*}}-\left(p-s_{R}-(1-\lambda)\left(s_{M}-s_{R}\right)\right) \\
& \times \int_{0}^{Q^{a c^{*}}} F(x) d x .
\end{aligned}
$$
is

By the same logic, the manufacturer's real expected profit

$$
\pi_{M}^{a c^{*}}=(w-c) Q^{a c^{*}}+\lambda\left(s_{M}-s_{R}\right) \int_{0}^{Q^{a c^{*}}} F(x) d x .
$$

And the real expected profit of the whole supply chain is

$$
\pi^{a c^{*}}=(p-c) Q^{a c^{*}}-\left(p-s_{M}\right) \int_{0}^{Q^{a c^{*}}} F(x) d x .
$$

Since $\partial \pi^{a c^{*}} / \partial Q^{a c^{*}}=0$, we can obtain that $Q^{a c^{*}}=F^{-1}[(p-$ $\left.c) /\left(p-s_{M}\right)\right]$, which is not necessarily equal to (16). Here we mark that $Q^{N c^{*}}=F^{-1}\left[(p-c) /\left(p-s_{M}\right)\right]$. When the retailer chooses $Q^{N c^{*}}$, the profit of the whole supply chain is maximized. Furthermore, from (19), the bigger the ordering quantity deviates from $Q^{N c^{*}}$, the bigger the profit deviates from the maximum profit.

Compared with the basic newsvendor model, the profit difference is

$$
\begin{aligned}
\Delta \pi= & \pi^{N^{*}}-\pi^{a c^{*}}=(p-c)\left(Q^{N^{*}}-Q^{a c^{*}}\right) \\
& -\left(p-s_{R}\right) \int_{0}^{Q^{N^{*}}} F(x) d x+\left(p-s_{M}\right) \\
& \times \int_{0}^{Q^{a c^{*}}} F(x) d x .
\end{aligned}
$$

Corollary 4. When $\mathrm{Q}^{N^{*}}>2 \mu$, then $\mathrm{Q}^{N c^{*}}>\mathrm{Q}^{N^{*}}>\mathrm{Q}_{a}^{*}$ and $Q^{N c^{*}}>Q^{a c^{*}}>Q_{a}^{*}$; when $Q^{N^{*}}<2 \mu$, then $Q^{a c^{*}}>Q_{a}^{*}>Q^{N^{*}}$ and $Q^{N c^{*}}>Q^{N^{*}}$.

Proof. For any $Q^{N^{*}}$, we have $Q^{N c^{*}}=F^{-1}\left[(p-w) /\left(p-s_{M}\right)\right]>$ $F^{-1}\left[(p-w) /\left(p-s_{R}\right)\right]=Q^{N^{*}}$ and $Q^{a c^{*}}>Q_{a}^{*}$. When $Q^{N^{*}}>2 \mu$, we can obtain $Q^{N^{*}}>Q_{a}^{*}$ from Corollary 2 and then obtain $Q^{N c^{*}}>Q^{N^{*}}>Q_{a}^{*}$.

Here we mark that $Q^{\prime}=F_{a}^{-1}\left[(p-w) /\left(p-s_{M}\right)\right]$; then, $Q^{\prime}>Q^{a c^{*}}$. It is easy to see that $Q^{\prime}=(1-a) Q^{N c^{*}}+2 a \mu$ which is similar to the proof of Theorem 1 . When $Q^{N c^{*}}>2 \mu$, we have $Q^{N c^{*}}>Q^{\prime}$ and $Q^{N c^{*}}>Q^{a c^{*}}$, and then $Q^{N c^{*}}>Q^{a c^{*}}>Q_{a}^{*}$. When $Q^{N^{*}}<2 \mu$, we obtain $Q_{a}^{*}>Q^{N^{*}}$ from Corollary 2; therefore, $Q^{a c^{*}}>Q_{a}^{*}>Q^{N^{*}}$.

Corollary 5. When $Q^{N^{*}}>2 \mu$, then $\pi^{N c^{*}}>\pi^{a c^{*}}$, and the bigger $a$ is, the bigger the expected profit of the whole supply chain deviates from the maximum profit. 
Proof. In the case of $Q^{N^{*}}>2 \mu$, when the retailer chooses $Q^{N c^{*}}$, the manufacturer can coordinate supply chain to maximize his profit; therefore, we have $\pi^{N c^{*}}>\pi^{a c^{*}}$. Here we mark that the rational optimal ordering quantity is $Q^{c^{*}}=$ $F^{-1}\left((p-w) /\left(p-s_{R}-(1-\lambda)\left(s_{M}-s_{R}\right)\right)\right)$ and the profit is $\pi^{c^{*}} ;$ thus, $\pi^{c^{*}}-\pi^{a c^{*}}=(p-c)\left(Q^{c^{*}}-Q^{a c^{*}}\right)-\left(p-s_{M}\right) \int_{Q^{a c^{*}}}^{Q^{c^{*}}} F(x) d x$. According to the proof of Corollary 3 , we concluded that the profit of the whole supply chain decreases with $a$. Since $\pi^{N c^{*}}$ and $\pi^{c^{*}}$ are fixed, we draw the conclusion that the bigger $a$ is, the bigger the expected profit of the whole supply chain deviates from the maximum profit.

Compared with the basic newsvendor model, the residual value of the unit product in the manufacturer is more than that in the retailer in the cooperation mode. Moreover, in the specific market environment, the manufacturer can make $Q^{a c^{*}}$ closer to $Q^{N c^{*}}$ through adjusting the size of $\lambda$.

Apparently, the retailer's ordering quantity is affected mainly by the retailer's overconfident level $a$, demand mean $\mu$, and the variance $\sigma^{2}$. In this section, we provide a numerical study to examine the impacts of the retailer's overconfident behavior on the optimal ordering quantity and profits. We assume that the market demand follows a normal distribution $N \sim\left(60,150^{2}\right), p=24, w=9, c=6, s_{M}=5$, and $s_{R}=4$, and we calculate that the retailer's optimal ordering quantity is 161.1735 , the retailer's profit is 637.9868, the manufacturer's profit is 483.5204 , and the profit of the supply chain is 1121.5072 under the basic newsvendor model. We first analyze the circumstance of $Q^{N^{*}}>2 \mu$, and then let $\lambda=0.5$, and the specific dates are listed in Table 1 .

From Table 1, the result that $Q_{a}^{*}$ and $Q^{a c^{*}}$ decrease with $a$ may be different from our expectations. Many psychologists and scholars give explanations, such as Schweitzer and Cachon [4] who found that when the market is in a highprofit environment, decision-makers tend to order less and when the market is in a low-profit environment, decisionmakers tend to order more. In addition, $\pi_{a}^{*}$ deviates from $\pi^{N^{*}}$, which also examines the validity of Corollary 3 . For a fixed $a$, if $\lambda$ decreases, then the retailer increases her ordering quantity, making the profit of the whole supply chain increase. Therefore, increasing the incentive properly can improve the performance of the supply chain, but it does not ensure that profits of the retailer and the manufacturer increase jointly.

Figure 1 shows an illustration of how $\pi^{a c^{*}}, \pi^{N^{*}}$, and $\pi_{a}^{*}$ vary with $\lambda$ and $a$. In cooperation mode, when the retailer's overconfident level is low, we have $\pi^{a c^{*}}>\pi^{N^{*}}$. This can be explained as follows. The main reason is that the manufacturer has the advantage in disposing of the unsold products compared with the retailer, which made the increased profit through cooperation larger than the loss caused by the ordering quantity deviation, and the retailer increases her ordering quantity when motivated by the manufacturer which made the total profit increase.

The results of Figures 2 and 3 indicate the impact of the overconfident level on expected profits of the retailer and manufacturer under different allocation rate $\lambda$. To be specific,
TABLE 1: The optimal quantity and expected profits under different overconfident level.

\begin{tabular}{lccclll}
\hline$a$ & $Q_{a}^{*}$ & $\pi_{a}^{*}$ & $Q^{a c^{*}}$ & $\pi^{a c^{*}}$ & $\pi_{R}^{a c^{*}}$ & $\pi_{M}^{a c^{*}}$ \\
\hline 0 & 161 & 1121 & 170 & 1243 & 684 & 559 \\
0.1 & 157 & 1108 & 165 & 1225 & 683 & 542 \\
0.2 & 152 & 1095 & 160 & 1207 & 682 & 525 \\
0.3 & 148 & 1081 & 155 & 1187 & 679 & 508 \\
0.4 & 144 & 1066 & 150 & 1167 & 675 & 491 \\
0.5 & 140 & 1050 & 145 & 1145 & 671 & 474 \\
0.6 & 136 & 1034 & 140 & 1122 & 665 & 457 \\
0.7 & 132 & 1016 & 135 & 1098 & 658 & 440 \\
0.8 & 128 & 998 & 130 & 1073 & 649 & 423 \\
0.9 & 124 & 979 & 125 & 1047 & 640 & 406 \\
1 & 120 & 960 & 120 & 1020 & 630 & 390 \\
\hline
\end{tabular}

TABLE 2: The optimal quantity and expected profits under different overconfident level.

\begin{tabular}{lcccccc}
\hline$a$ & $Q_{a}^{*}$ & $\pi_{a}^{*}$ & $Q^{a c^{*}}$ & $\pi^{a c^{*}}$ & $\pi_{R}^{a c^{*}}$ & $\pi_{M}^{a c^{*}}$ \\
\hline 0 & 73 & 993 & 74 & 1014 & 781 & 232 \\
0.1 & 78 & 1004 & 79 & 1026 & 778 & 248 \\
0.2 & 82 & 1009 & 83 & 1034 & 770 & 263 \\
0.3 & 87 & 1009 & 88 & 1038 & 758 & 279 \\
0.4 & 92 & 1006 & 92 & 1039 & 744 & 295 \\
0.5 & 96 & 1001 & 97 & 1038 & 727 & 310 \\
0.6 & 101 & 994 & 101 & 1035 & 709 & 326 \\
0.7 & 106 & 986 & 106 & 1032 & 689 & 342 \\
0.8 & 110 & 978 & 110 & 1028 & 670 & 358 \\
0.9 & 115 & 969 & 115 & 1024 & 650 & 374 \\
1 & 120 & 960 & 120 & 1020 & 630 & 390 \\
\hline
\end{tabular}

when the overconfident level $a$ is low, for example, when $a<0.4$, the expected profits of the retailer and manufacturer increase, which achieves the Pareto improvement, compared with the basic newsvendor model. For a fixed $a, \pi_{R}^{a c^{*}}$ and $\pi^{a c^{*}}$ increase with the allocation rate $1-\lambda$, while $\pi_{M}^{a c^{*}}$ decreases with it. Besides, when $a$ exceeds a threshold, the expected profits of the retailer and the manufacturer become smaller; thus, the supply chain profit is less than that in the basic newsvendor model. Therefore, from the manufacturer's perspective, when $a$ is low, he can offer incentives to the retailer. However, when $a$ increases, he should reduce the allocation proportion $1-\lambda$ to the retailer to ensure that their expected profit is no less than $\pi_{M}^{N^{*}}$.

Next, we use another example to illustrate the impact of the overconfident behavior on the supply chain. We discuss the scenario of $Q^{N^{*}}<2 \mu$. In this example, the market demand follows the normal distribution $X \sim N\left(60,20^{2}\right)$ and the values of other variables remain unchanged. The retailer's optimal quantity is 73.4898 and profit is 773.0422 and the manufacturer's profit is 220.4694 and the profit of the supply chain is 993.5116 under the basic newsvendor model. Let $\lambda=$ 0.5 and specific data values are listed in Table 2 . 


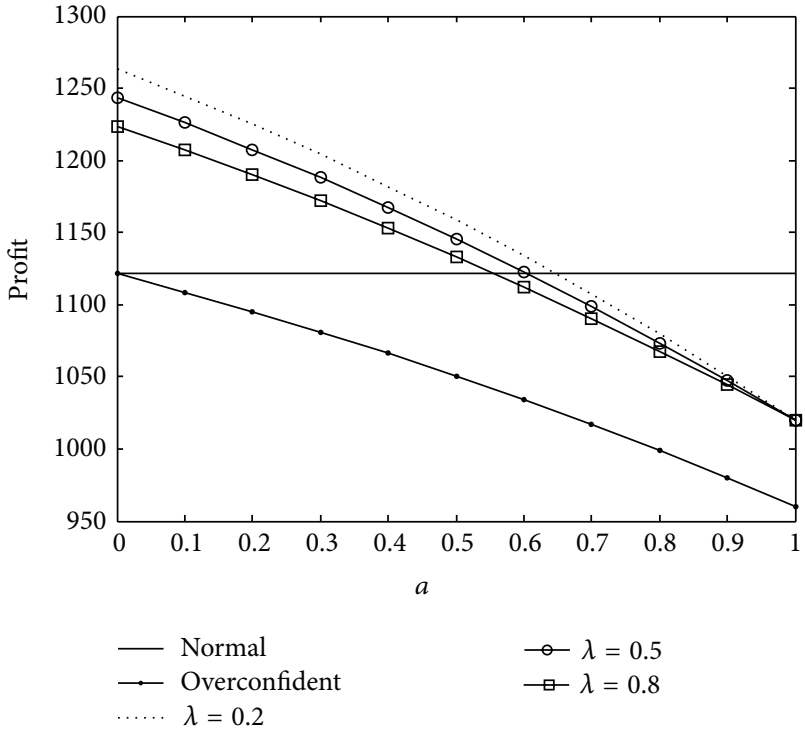

FIGURE 1: The expected profit of the supply chain under different allocation rate $\lambda$.

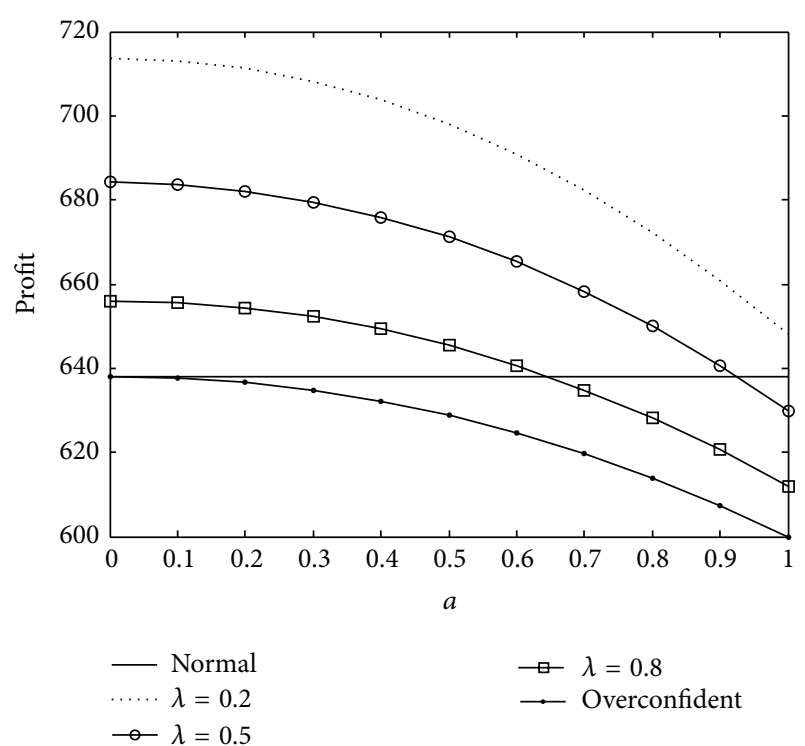

FIGURE 2: The retailer's expected profit under different allocation rate $\lambda$.

From Table 2, the equation $\pi_{M}^{a c^{*}}>\pi_{M}^{N^{*}}$ implied that the manufacturer can obtain more profits when the retailer is overconfident. Besides, $Q_{a}^{*}$ increases and $\pi_{a}^{*}$ increases first and then decreases with $a$. These results mean that the retailer's overconfident behavior does not necessarily damage the supply chain. Meanwhile, if the manufacturer offers proper incentive to the retailer, the whole supply chain can achieve Pareto improvement. For example, when $\lambda=0.5$ and $a$ is in a reasonable range, $\pi_{M}^{a c^{*}}>\pi_{M}^{N^{*}}$ and $\pi_{R}^{a c^{*}}>\pi_{R}^{N^{*}}$ hold. However, when $a$ exceeds a threshold, the manufacturer's incentive has little impact on the retailer's ordering decision and the retailer's overconfident behavior

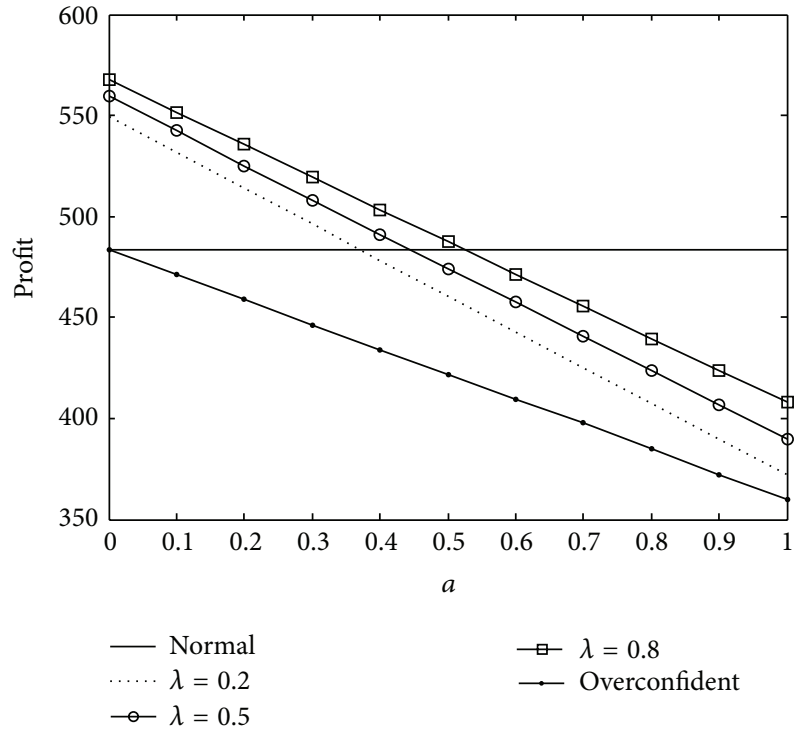

FIGURE 3: The manufacturer's expected profit under different allocation rate $\lambda$.

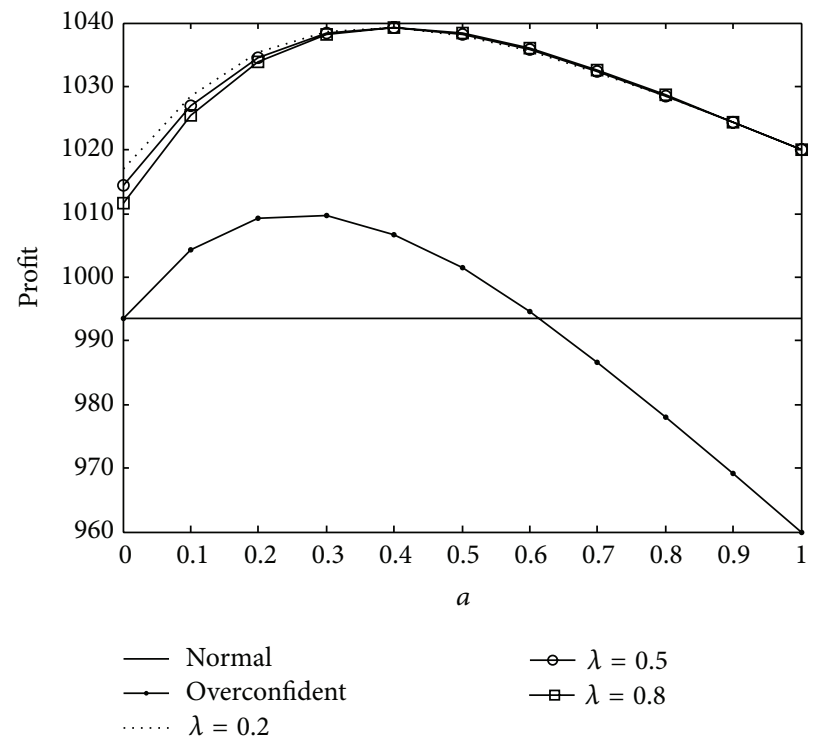

FIGURE 4: The expected profit of the supply chain under different allocation rate $\lambda$.

brings more losses to the supply chain. In particular, when $a=$ 1 , the manufacturer's incentive cannot impact the retailer's ordering decision.

In order to illustrate the profit variance, we take different $\lambda$ as presented in Figures 4-6.

We can see from Figure 4 that when $\lambda=1$, the manufacturer does not provide any incentives, and with the increase of $a$, the profit of the whole supply chain is higher first and then lower than that in the basic newsvendor model, which examines the validity of Corollary 3. When the overconfident level $a$ is in a reasonable range, the profit of the whole supply chain increases with the allocation rate $1-\lambda$; when $a$ exceeds a threshold, the profit of the whole supply 


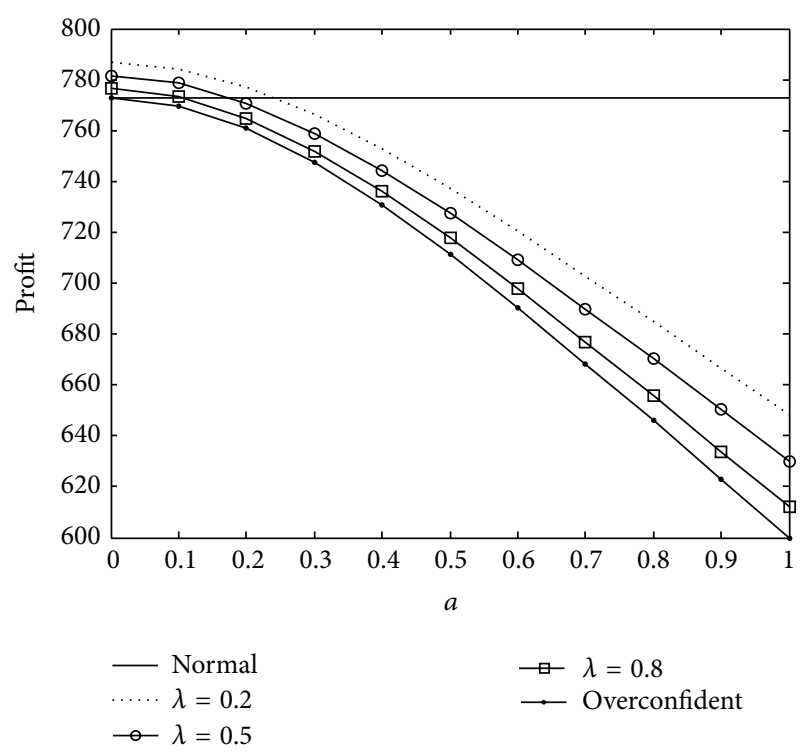

Figure 5: The retailer's expected profit under different allocation rate $\lambda$.

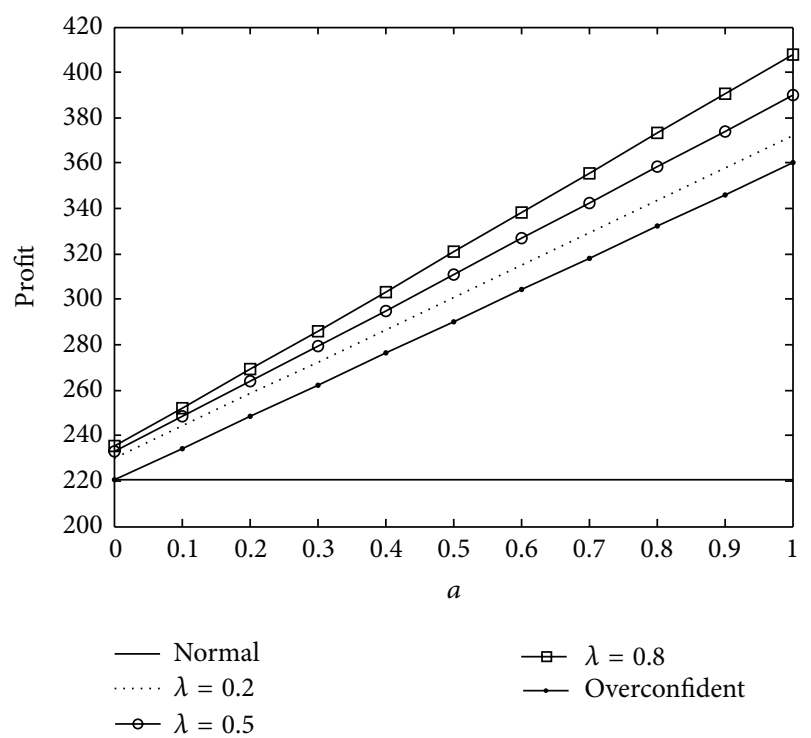

FIgURE 6: The manufacturer's expected profit under different allocation rate $\lambda$.

chain has a downward trend, and the change of $\lambda$ has little impact on the profit. From Figures 5 and 6 , we have $\pi_{M}^{a c^{*}}>$ $\pi_{M}^{N^{*}}$, regardless of the change of $a$; that is, the manufacturer can achieve Pareto improvement. We observe that a lower allocation rate $\lambda$ allows a higher overconfident level $a$. When $a$ is low, the incentive can make up for the losses caused by more orders, so $\pi_{R}^{a c^{*}}>\pi_{R}^{N^{*}}$; when $a$ is high, the retailer's order deviates from the optimal order.

It is worth pointing that the demand variance has a tremendous impact. For example, when the demand distribution follows $X \sim N\left(60,75^{2}\right)$ and the other variables remain unchanged, whatever $a$ is, the manufacturer's profit is higher than that in the basic newsvendor model, so when the manufacturer transfers all the residual value to the retailer, that is, $\lambda=0$, we have calculated that the manufacturer's and retailer's profit increase whatever $a$ is compared with basic newsboy model, which can achieve the Pareto improvement and examines the validity of Corollary 3.

6.2. Buyback Mode. In this mode, the manufacturer designs a buyback contract to encourage the retailer to order more products, the manufacturer buys back the unsold products and the buyback price is $b$, and $b>s_{R}$, which is to ensure that the buyback price is higher than the value of the retailer's disposals. It is easy to see that, compared with the basic newsvendor model, the retailer can get more profits when the ordering quantity is the same.

When $b=0$, the manufacturer does not take back unsold products; when $b=s_{R}$, the retailer's expected profit is the same no matter who deals with unsold products; when $b=$ $s_{M}$, the manufacturer transfers all the benefit from the unsold products to the retailer; when $b=w$, the retailer has no ordering risk.

In the Stackelberg game, the manufacturer is the leader and the retailer is the follower. The chronology of the game event is given as follows. Firstly, before the selling season, the manufacturer informs the retailer about the wholesale price and the buyback price. Secondly, the retailer determines her ordering quantity $Q$ based on this information. At the end of the selling season, the manufacturer pays $b$ for the unsold products to the retailer.

Similar to the basic model, the retailer's real expected profit is $\pi_{R}^{a b}=E\left\{p S^{b}\left(Q^{a b}\right)+b I^{b}\left(Q^{a b}\right)-w Q^{a b}\right\}$.

It can be simplified as $\pi_{R}^{a b}=(p-w) Q^{a b}-(p-$ b) $\int_{0}^{Q^{a b}} F(x) d x$.

From the above equation, the optimal ordering quantity is $Q^{a b^{*}}=F_{a}^{-1}[(p-w) /(p-b)]$. $Q^{a b^{*}}$ is decreasing in $w$ and increasing in $b$. That is, the retailer hopes for a lower wholesale price and a higher buyback price.

In the buyback mode, the manufacturer's real expected profit is $\pi_{S}^{a b^{*}}=(w-c) Q^{a b^{*}}+\left(s_{M}-b\right) \int_{0}^{Q^{a b^{*}}} F(x) d x$ and the real expected profit of whole supply chain is $\pi^{a b^{*}}=(p-c) Q^{a b^{*}}$ $\left(p-s_{M}\right) \int_{0}^{Q^{a b^{*}}} F(x) d x$.

Compared with the basic newsvendor model, the profit difference is

$$
\begin{aligned}
\Delta \pi= & \pi^{N^{*}}-\pi^{a b^{*}}=(p-c)\left(Q^{N^{*}}-Q^{a b^{v}}\right) \\
& -\left(p-s_{R}\right) \int_{0}^{Q^{N^{*}}} F(x) d x \\
& +\left(p-s_{M}\right) \int_{0}^{Q^{a b^{*}}} F(x) d x .
\end{aligned}
$$

Therefore, the manufacturer can adjust the wholesale price $w$ and the buyback price $b$ to make the retailer's ordering decision closer to the optimal ordering quantity and then make the whole supply chain more efficient. If $b<s_{R}$, 


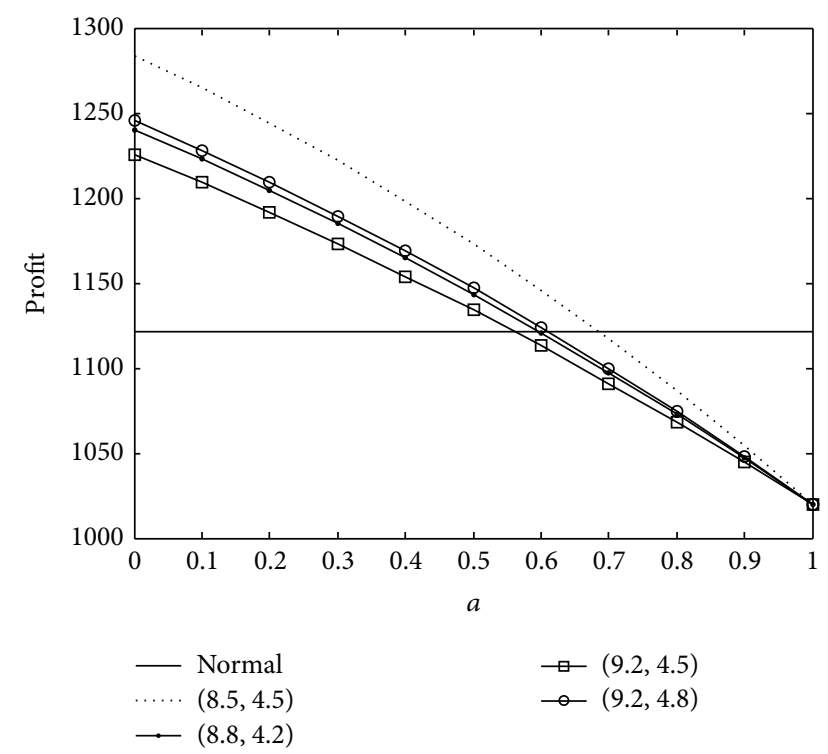

Figure 7: The expected profit of the supply chain under different $w$ and $b$.

the retailer does not sell unsold products to the manufacturer, so the manufacturer must keep $b>s_{R}$.

First, we discuss the scenario that $Q^{N^{*}}>2 \mu$. The demand follows the normal distribution $X \sim N\left(60,150^{2}\right)$, and the values of other variables remain the same except $w$ and $b$. Furthermore, the profits of the whole supply chain, the retailer, and the manufacturer are shown in Figures 7-9, respectively.

From Figure 7, the lower the wholesale price is and the higher the buyback price is, the greater the total profit is. This is because of the fact that a lower $w$ can encourage the retailer to increase her ordering quantity. We find it difficult to make the ordering quantity $F^{-1}[(p-w) /(p-b)]$ equal to $F^{-1}\left[(p-c) /\left(p-s_{M}\right)\right]$. Therefore, in order to increase the profit of the whole supply chain, the manufacturer should offer incentives (such as improving the buyback price and reducing the wholesale price) on the premise that his profit is higher than that in the basic model.

From Figures 8 and 9, when the incentives are larger, that is, when $w$ is smaller and $b$ is bigger, apparently, the retailer's profit increases. As is shown in Figure 8, when $w=8.5$ and $b=4.5$, the retailer's profit and the profit of the whole supply chain are significantly higher than other cases, but the manufacturer's profit is lower than other cases.

Note that as long as $a$ is in a reasonable range, the supply chain can be coordinated. However, when $a$ exceeds a threshold, the whole supply chain cannot realize the Pareto improvement, and the reason is that since the manufacturer's improvement measures have weaker impact on the retailer, he considers his own profit and does not offer the retailer any incentive for avoiding or reducing the loss.

Next, we discuss the scenario of $Q^{N^{*}}<2 \mu$. The demand follows the normal distribution $N \sim\left(60,20^{2}\right)$, and the values of other variables remain the same except $w$ and $b$. The profits of the whole supply chain, the retailer, and the manufacturer are shown in Figures 10-12, respectively.

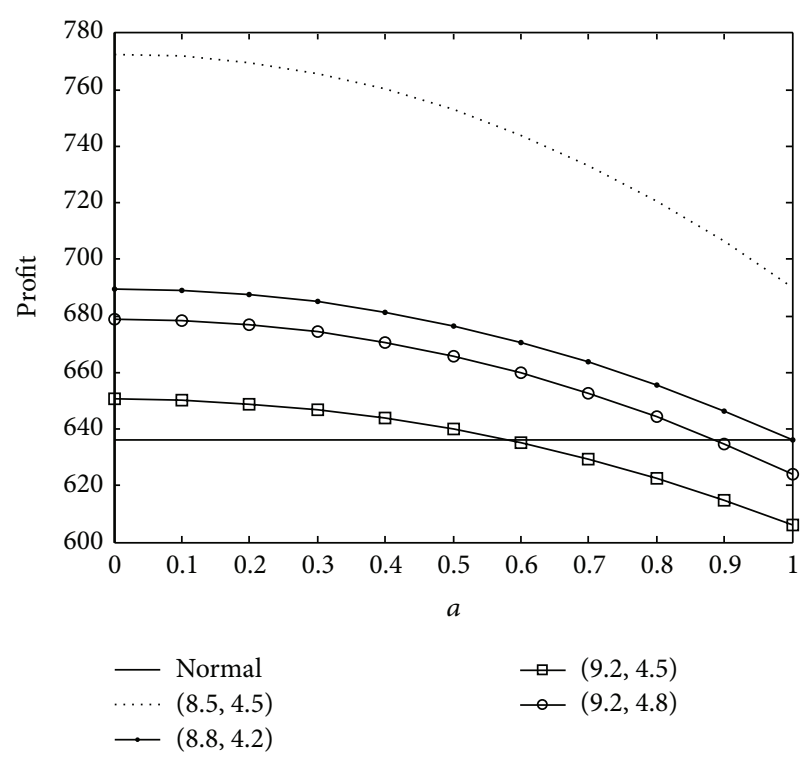

Figure 8: The retailer's expected profit under different $w$ and $b$.

Figure 10 illustrates when $a$ is low, increasing the incentive can increase the profit of the whole supply chain, and when $a$ is high, the incentive measure has little effect. Therefore, the manufacturer does not need to take more measures to support the retailer when $a$ is high.

The results of Figures 11 and 12 indicate the impact of the overconfident level on expected profits of the retailer and the manufacturer under different $(w, b)$. First of all, the manufacturer's profit increases with $a$, and this is because the retailer's ordering quantity increases with $a$. To achieve Pareto improvement, when $a$ is low, the manufacturer does not need to offer too many incentives; when $a$ is not very high, the manufacturer should offer more incentives to ensure that the retailer's profit is higher than that in the basic model. When $a$ exceeds a threshold, if the manufacturer sets $1-\lambda$ to a very high value, then the manufacturer's profit is less than that in the basic model; on the other hand, if the manufacturer sets $1-\lambda$ to a low value, the retailer's profit is less than that in the basic model.

We address the differences between this paper and Croson et al. [11]. First, different from the buyback contract and the wholesale price contract in Croson et al. [11], we analyze the cooperation mode and buyback mode. In this paper, the buyback price $b$ is larger than 0 , and strictly speaking, $b$ is larger than the salvage value $s_{R}$. However, in their paper, the buyback price can be lower than 0 . If it is negative, the retailer does not sell unsold products to the manufacturer. Secondly, in our paper, the manufacturer can make the retailer and the manufacturer achieve Pareto improvement by adjusting $b$ and $w$. They do not consider the change of the retailer's and manufacturer's profit after the implementation of the contract.

6.3. Results Analysis. The comparison of the two modes: in the cooperation mode, the manufacturer and retailer can better exchange information and views; meanwhile, it enables 


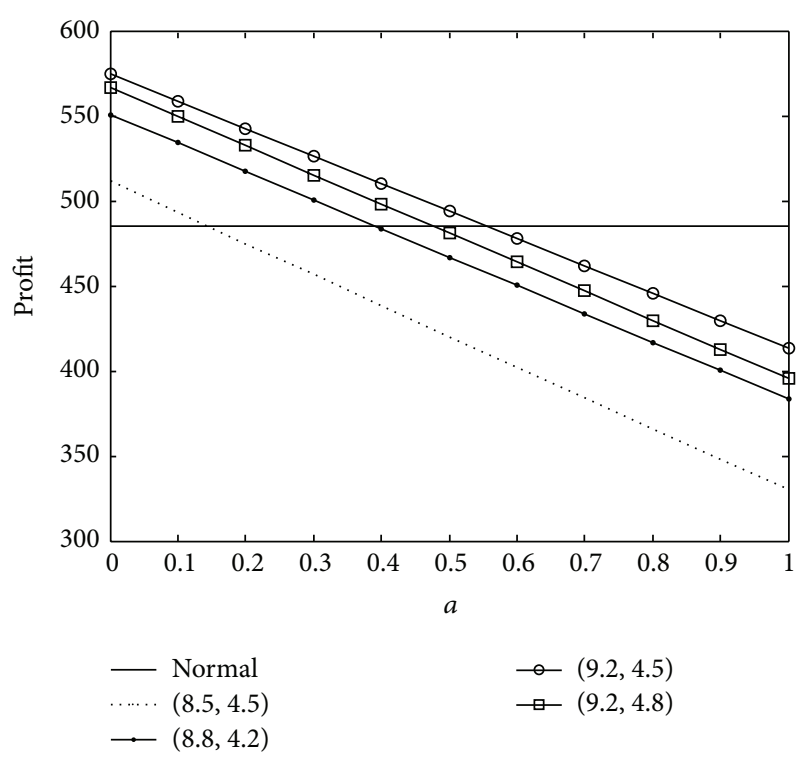

Figure 9: The manufacturer's expected profit under different $w$ and $b$.

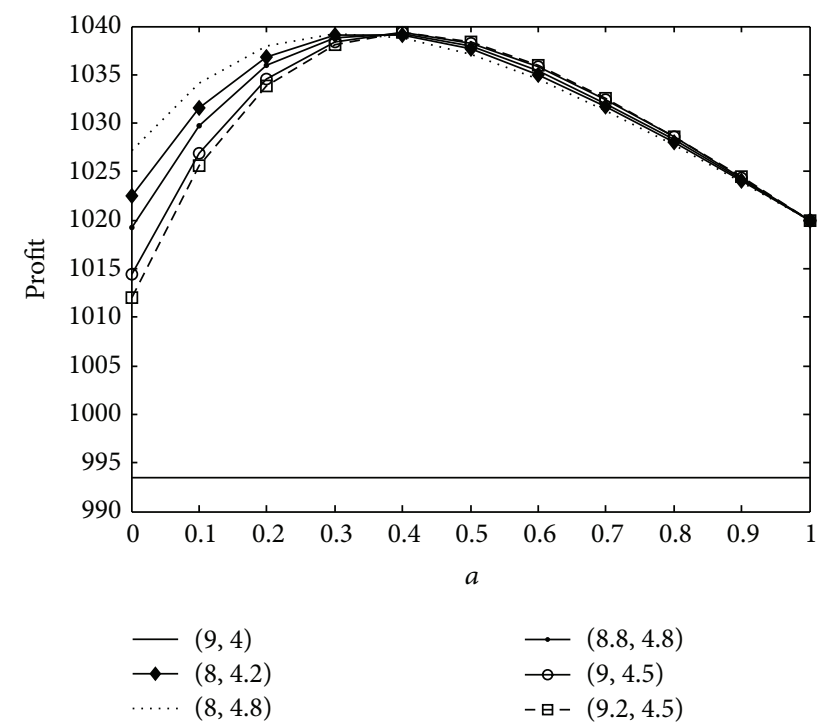

FIGURE 10: The expected profit of the supply chain under different $w$ and $b$.

the retailer to listen to the manufacturer's recommendations, which is useful for reaching the Pareto improvement by reallocating the residual value of the unsold products; while in the buyback mode, the manufacturer can adjust the wholesale price and the buyback price, and the range of $b$ is larger than $s_{R}+(1-\lambda)\left(s_{M}-s_{R}\right)$. In the buyback mode, in the scenario of $Q^{N^{*}}>2 \mu$, when $a$ is high, the manufacturer can reduce the wholesale price $w$. In the scenario of $Q^{N^{*}}<2 \mu$, when $a$ is high, the manufacturer can increase the wholesale price $w$. In the cooperation mode, the manufacturer can do little when $a$ is high.

In the wholesale price contract, only $w$ can be changed, while in the buyback contract, not only $w$ but also $b$ can be

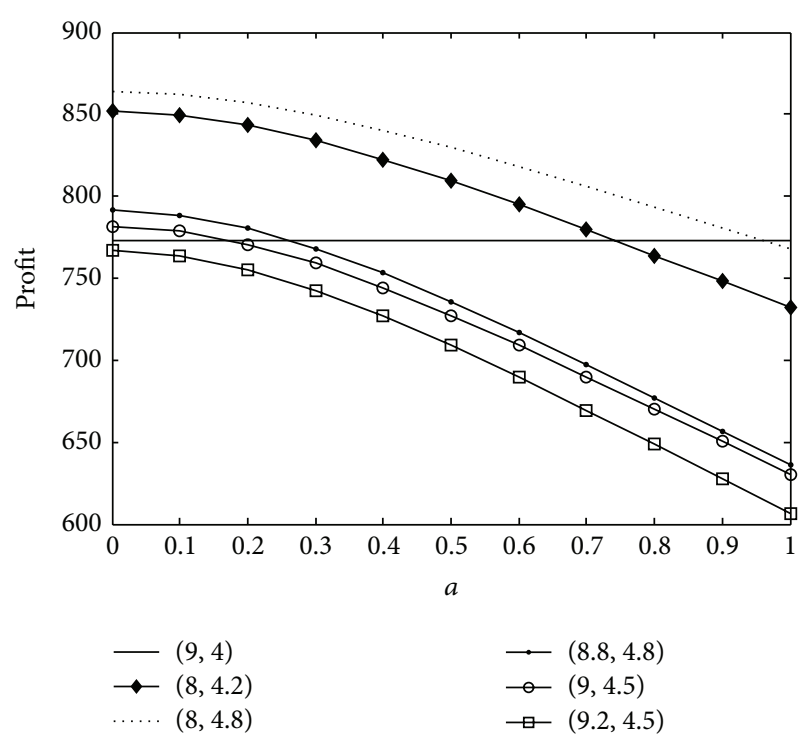

FIGURE 11: The retailer's expected profit under different $w$ and $b$.

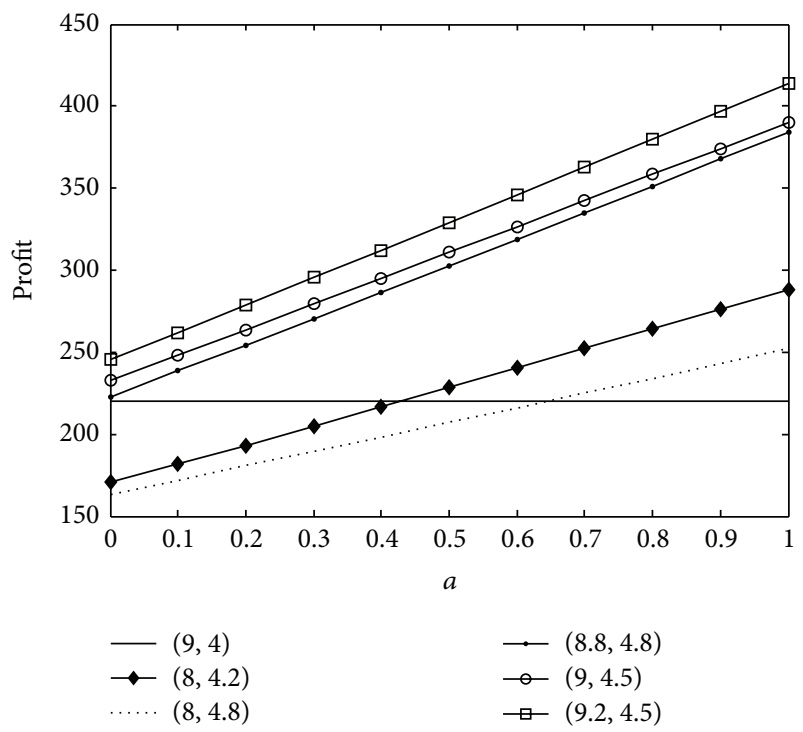

FIGURE 12: The manufacturer's expected profit under different $w$ and $b$.

changed. In the wholesale price contract, the manufacturer may realize Pareto improvement by reducing $w$ when $a$ is low. In the buyback mode, $w$ can be increased or reduced, and the supply chain can realize the Pareto improvement when $a$ is low, and the manufacturer can also gain more profits by changing $(w, b)$, and it is difficult in the wholesale price contract. As the retailer's overconfident behavior may cause more ordering, the retailer must dispose of them by herself in the wholesale price contract; thus, we take the buyback contract to share the supply chain risk. In short, compared with the wholesale price contract and the cooperation mode, the buyback mode is the optimal choice for the manufacturer. 


\section{Conclusions}

Overconfident behavior has largely been overlooked in the supply chain management literature. This paper attempts to fill the gap. Our premise is that the retailer has overconfident behavior on the market demand. In this setting, we start with a basic model and analyze the retailer's optimal ordering decision. In the model of overconfident newsvendor, we analyze the overconfident retailer's optimal ordering decision and compare the optimal ordering decisions in the traditional and overconfident newsvendor models. We find that when $Q^{N^{*}}>2 \mu$, the expected profit of the whole supply chain in the overconfident newsvendor model is less than that in the basic newsvendor model, and with the retailer's overconfidence level increasing, the expected profit of the whole supply chain decreases. When $Q^{N^{*}}<2 \mu$, with the retailer's overconfidence level increasing, the expected profit of the whole supply chain in the overconfident newsvendor model has two cases: it is either higher or higher first and then lower than that in the basic newsvendor model. In other words, overconfident behavior does not necessarily damage the supply chain.

In terms of ordering deviation and profit losses caused by the retailer's overconfident behavior, we discuss two mechanisms: the cooperation mode and the buyback mode. Besides, we reallocate the residual value of the unsold products in them creatively in the cooperation mode and analyze the ordering decision by the Stackelberg game in the two modes. Moreover, we document the results of a numerical study to further illustrate the effects of the overconfident level on the ordering quantity and profits. We find that when $a$ is low, the supply chain can achieve Pareto improvement by reasonable incentive. When $a$ exceeds a threshold, the whole supply chain cannot realize the Pareto improvement, and at this time since the manufacturer's improvement measures have weaker impact on the retailer, the retailer's ordering decision cannot make the whole supply chain sustainable development. Therefore, it is harmful for the supply chain when the overconfident level is high.

There are several directions for future research. First, the manufacturer needs to design contracts to manage the retailer's overconfident behavior and coordinate supply chain and it would be an important topic in the future. Besides, in practice, the manufacturer generally franchises more than one retailer to sell their products; thus, considering two or more retailers to compete in selling could present interesting opportunities for future research.

\section{Conflict of Interests}

The authors declare that there is no conflict of interests regarding the publication of this paper.

\section{Acknowledgments}

The authors sincerely thank the editor and the anonymous reviewers for their constructive and important comments on the paper. Lei Xu's research is partially supported by the National Natural Science Foundation of China, Grant no. 71302005; Humanities and Social Sciences Foundation of Ministry of Education in China, Grant no. 14YJC630049; and the Scientific Development Strategy Project of Tianjin, Grant no. 13ZLZLZF03500.

\section{References}

[1] D. Kahneman, Thinking, Fast and Slow, Macmillan, London, UK, 2011.

[2] B. B. Moritz, A. V. Hill, and K. L. Donohue, "Individual differences in the newsvendor problem: behavior and cognitive reflection," Journal of Operations Management, vol. 31, no. 1, pp. 72-85, 2013.

[3] M. Fisher and A. Raman, "Reducing the cost of demand uncertainty through accurate response to early sales," Operations Research, vol. 44, no. 1, pp. 87-99, 1996.

[4] M. E. Schweitzer and G. P. Cachon, "Decision bias in the newsvendor problem with a known demand distribution: experimental evidence," Management Science, vol. 46, no. 3, pp. 404-420, 2000.

[5] X. Su, "Bounded rationality in newsvendor models," Manufacturing and Service Operations Management, vol. 10, no. 4, pp. 566-589, 2008.

[6] Y. Funakia, J. Ting, and J. Pottersc, "Eye tracking social preferences," Working Paper, 2014.

[7] C. Li and A. M. Davis, "Validating Models for Bounded Rationality and Decision Biases in a Newsvendor Experiment," 2014.

[8] M. Glaser and M. Weber, Over-Confidence and Trading Volume, Working paper, Universität Mannheim, Mannheim, Germany, 2003.

[9] U. Malmendier and G. Tate, "CEO overconfidence and corporate investment," Journal of Finance, vol. 60, no. 6, pp. 26612700, 2005.

[10] J. E. Russo and P. Schoemaker, "Managing overconfidence," Sloan Management Review, vol. 33, no. 2, pp. 7-17, 1992.

[11] D. Croson, R. Croson, and Y. Ren, "How to manage an overconfident newsvendor," Working Paper, Southern Methodist University, 2008.

[12] K. J. Arrow, T. Harris, and J. Marschak, "Optimal inventory policy," Econometrica, vol. 19, pp. 250-272, 1951.

[13] T. M. Whitin, "Inventory control and price theory," Management Science, vol. 2, no. 1, pp. 61-68, 1955.

[14] R. B. Thakkar, D. R. Finley, and W. M. Liao, "A stochastic demand CVP model with return on investment criterion," Contemporary Accounting Research, vol. 1, no. 1, pp. 77-86, 1984.

[15] M. Khouja, "The single-period (news-vendor) problem: literature review and suggestions for future research," Omega, vol. 27, no. 5, pp. 537-553, 1999.

[16] N. C. Petruzzi and M. Dada, "Pricing and the newsvendor problem: a review with extensions," Operations Research, vol. 47, no. 2, pp. 183-194, 1999.

[17] Y. Qin, R. Wang, A. J. Vakharia, Y. Chen, and M. M. Seref, "The newsvendor problem: review and directions for future research," European Journal of Operational Research, vol. 213, no. 2, pp. 361-374, 2011.

[18] L. Eeckhoudt, C. Gollier, and H. Schlesinger, "The risk averse (and prudent) newsvendor," Management Science, vol. 41, no. 5, pp. 786-794, 1995.

[19] U. Benzion, Y. Cohen, R. Peled, and T. Shavit, "Decision-making and the newsvendor problem: an experimental study," Journal 
of the Operational Research Society, vol. 59, no. 9, pp. 1281-1287, 2008.

[20] S. Plous, The Psychology of Judgment and Decision Making, McGraw-Hill Book, 1993.

[21] F. Richard, "Behavioral finance in a principal-agent model of capital budgeting," Working Paper, University of Bath, 2004.

[22] S. Gervais, J. B. Heaton, and T. Odean, "The positive role of overconfidence and optimism in investment policy," Working Paper, University of California, Oakland, Calif, USA, 2002.

[23] D. A. Moore and P. J. Healy, "The trouble with overconfidence," Psychological Review, vol. 115, no. 2, pp. 502-517, 2008.

[24] Y. Ren and R. Croson, "Overconfidence in newsvendor orders: an experimental study," Management Science, vol. 59, no. 11, pp. 2502-2517, 2013.

[25] T. Proeger and L. Meub, "Overconfidence as a social bias: experimental evidence," Economics Letters, vol. 122, no. 2, pp. 203-207, 2014.

[26] B. A. Pasternack, "Optimal pricing and returns policies for perishable commodities," Marketing Science, vol. 4, no. 2, pp. 166-176, 1985.

[27] H. Herz, D. Schunk, and C. Zehnder, "How do judgmental overconfidence and overoptimism shape innovative activity?" Games and Economic Behavior, vol. 83, pp. 1-23, 2014.

[28] T. M. Choi, Y. Li, and L. Xu, "Channel leadership and performance under manufacturing/remanufacturing activities," International Journal of Production Economics, vol. 146, no. 1, pp. 371380, 2013.

[29] K. Govindan, M. N. Popiuc, and A. Diabat, "Overview of coordination contracts within forward and reverse supply chains," Journal of Cleaner Production, vol. 47, pp. 319-334, 2013.

[30] L. Xu, Y. Li, K. Govindan, and X. Xu, "Consumer returns policies with endogenous deadline and supply chain coordination," European Journal of Operational Research, 2014.

[31] J. B. Huang, N. Tan, and M. R. Zhong, "Incorporating overconfidence into real option decision-making model of metal mineral resources mining project," Discrete Dynamics in Nature and Society, vol. 2014, Article ID 232516, 11 pages, 2014. 


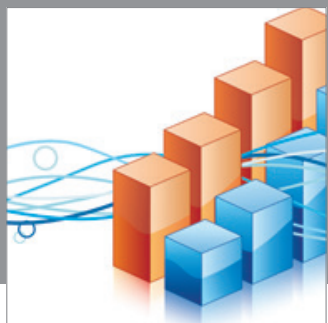

Advances in

Operations Research

mansans

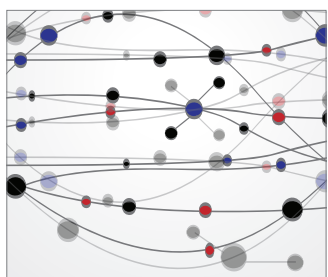

The Scientific World Journal
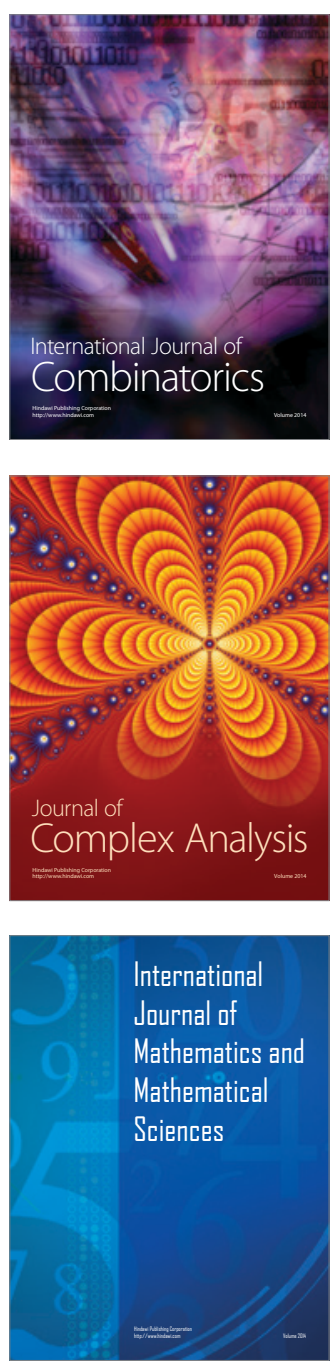
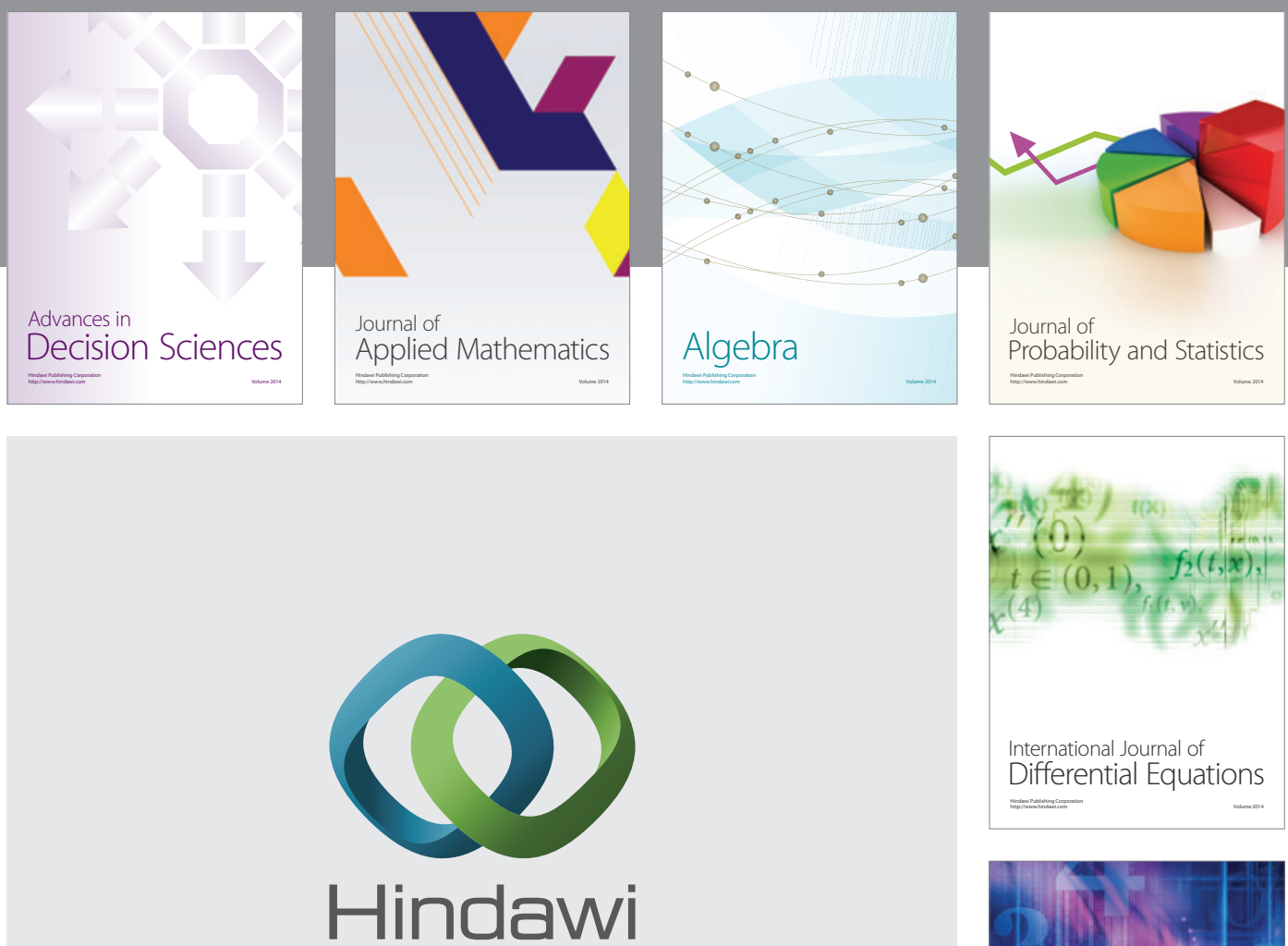

Submit your manuscripts at http://www.hindawi.com
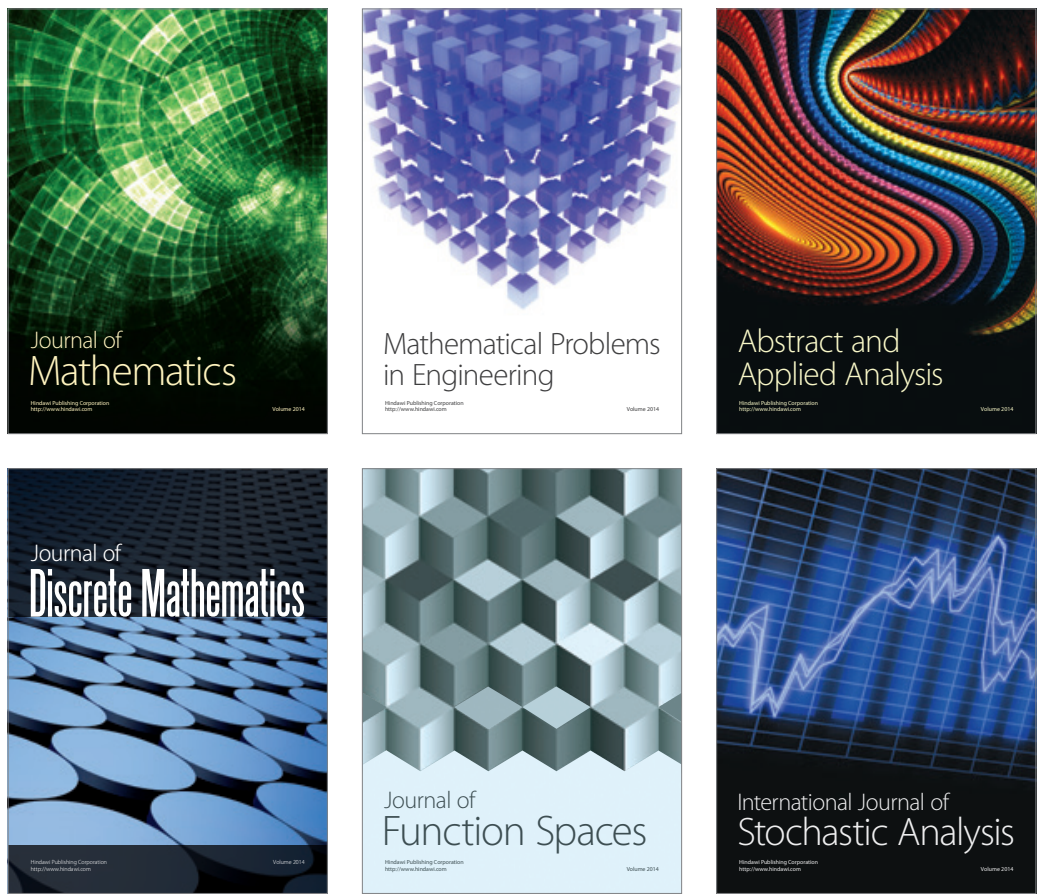

Journal of

Function Spaces

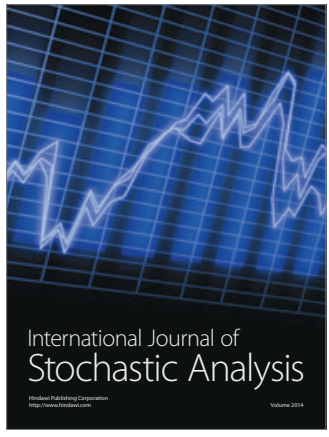

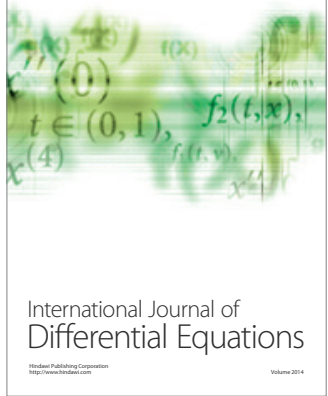
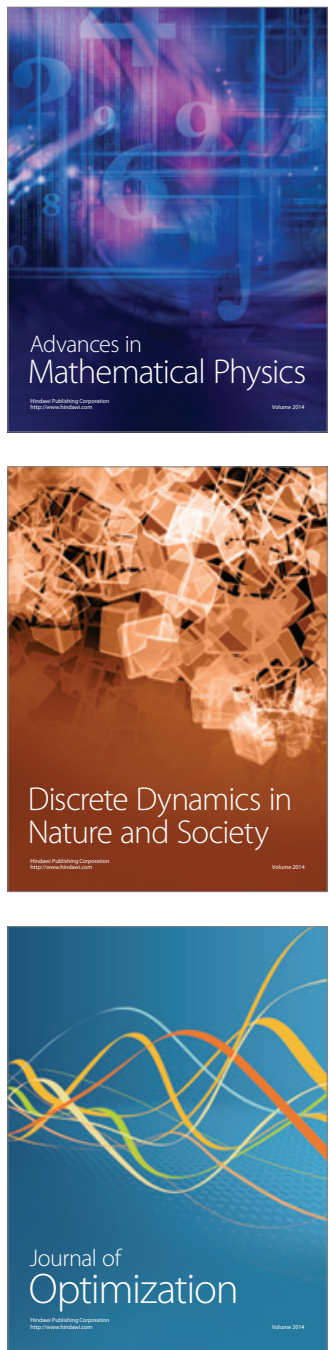